DOI: https://doi.org/10.30749/2594-8261.v1n1p50-60

\title{
O FUNDAMENTO DO DIREITO EM HEIDEGGER
}

\author{
THE BASIS OF LAW IN HEIDEGGER
}

Cleyson de Moraes Mello ${ }^{1}$

Resumo: A Constituição de 1988 representa uma mudança de paradigma no Direito brasileiro. A partir dessa mudança de modelo, é necessário investigar a realização do direito, a partir da tutela da dignidade da pessoa. O Direito alinhado a hermenêutica filosófica assume, pois, um viés transformador. Daí a necessidade de compreender o Direito a partir do ser-no-mundo. É, neste sentido que, em face da flagrante inefetividade da hermenêutica clássica, originariamente metodológica, torna-se necessária à construção de uma resistência teórica que aponte para a construção das condições de possibilidade da compreensão do direito, como modo de ser-no-mundo.

Palavras-chave: Direito. Dignidade humana. Ser-no-mundo. Dasein.

Abstract: The Constitution of 1988 represents a change of paradigm in the Brazilian law. From this change of model, it is necessary to investigate the performance of duty, from the protection of the dignity of the person. The legal thought cannot be designed from a predominantly caused by the limits of reason and built with the power of abstract rationality. It is in this sense that, given the striking ineffectiveness of classical hermeneutics, methodological in your origin, it is necessary to construct a theoretical strength that point to the construction of the conditions of possibility of understanding the law, as a way of being-in-the-world.

Keywords: Law. Human dignity. Being-in-the-world. Dasein.

\footnotetext{
${ }^{1}$ Professor Adjunto da Faculdade de Direito da UERJ. Departamento de Teorias e Fundamento do Direito. Diretor Adjunto da Faculdade de Direito de Valença - RJ; Professor Titular da Universidade Estácio de Sá - Rio de Janeiro - Brasil; Doutor e Mestre em Direito. profcleysonmello@hotmail.com.
} 


\section{AS FORMAS DE PENSAR}

A primeira forma de pensar é atribuída ao ser humano na forma de animal racional, diretamente referida à sua animalidade, característica intrínseca do ser vivo, "de um ser vivo que, como organismo, chegou a uma forma bem determinada de sua evolução". A segunda forma de pensar, na metafísica ocidental, era reduzida à lógica. Este pensar nos domínios da Filosofia era conhecido como metafísica e na ambiência das ciências como discurso lógico. De modo geral, neste segundo pensar, significava dizer que o ser humano era dotado de racionalidade. Para Heidegger, a terceira forma de pensar (pensar III), a mais importante, é o chamado pensar filosófico, daí designar este pensar como o mais digno de ser pensado.

O pensar filosófico consubstanciado pelos teoremas do círculo hermenêutico e da diferença ontológica, se impõe pela presença da lógica dos existenciais, ou seja, uma lógica oculta, uma lógica que é condição de qualquer conceito. A lógica existencial se diferencia da lógica das categorias, tendo em vista que esta relacionase à ontologia da coisa, àquela, à ontologia fundamental.

É, pois, uma mudança de paradigma no universo jurídico, sobretudo através da filosofia hermenêutica de Heidegger, objetivando uma visão crítica ao direito vigente na busca da construção de um novo marco teórico atrelado aos fundamentos do conhecimento jurídico.

\section{NOVOS PARADIGMAS}

O novo paradigma filosófico, visto a partir de um novo princípio epocal ${ }^{2}$ (é o

\footnotetext{
${ }^{2}$ Segundo Ernildo Stein (2004, p.141-142), o princípio epocal é o elemento essencial que assinala cada época da história da metafísica e deixa a sua marca em cada uma de suas manifestações. Heidegger enumera um conjunto de princípios epocais nos quais o ser é definido a partir de um ente. Assim, temos, por exemplo, a idéia em Platão, a substância em Aristóteles, o ipsum esse em Tomás de Aquino, o cogito em Descartes, o eu penso em Kant, o saber absoluto em Hegel, e a vontade de poder em Nietzsche. Cada uma dessas concepções de ser da metafísica termina marcando uma época. Por isso se fala em princípios epocais cujos traços aparecem, no fundo, em cada forma de cultura. [...]

Quando, hoje, falamos na Filosofia da Subjetividade e nela nos referimos à Filosofia transcendental e Filosofia dialética, estamos nos movimentando no interior de um princípio epocal como uma determinação paradigmática da modernidade. E, ao falarmos em fenomenologia que se ramifica em fenomenologia transcendental e fenomenologia hermenêutica, já rompemos com o princípio epocal
} 
tempo sem fundamento ${ }^{3}$ - sem princípio epocal determinante) da filosofia, deve ser introduzido na Filosofia do Direito, através da hermenêutica ontológico-existencial heideggeriana.

É o ser-aí, como ser-no-mundo, que descerra as portas para uma época em que a metafísica objetivista é deixada para trás, ou seja, é a fase em que a compreensão do ser é a compreensão dos entes em seu acontecer. Isto quer dizer que a metafísica não procura mais sua fundamentação em elementos últimos. $\mathrm{O}$ conceito de transcendental ${ }^{4}$ (não-clássico) deve ser orientado pela compreensão do ser que possui uma dimensão organizadora e estruturante no ser-aí e no conceito de mundo, ou seja, guiado para bem longe da relação entre consciência e mundo, da relação sujeito-objeto.

Neste sentido, Stein (2004, p. 144) esclarece

Assim, o standard de racionalidade que, de certo modo, estava
presente em cada princípio epocal, passa a assumir um sentido não-
objetivador, isto é, ele se refere a um acontecer que sempre se dá
em todos os nossos movimentos retóricos e argumentativos. Talvez
isso seja o mais significativo sinal de que fundamentar, depois de ter
diagnosticado a crise do fundamento, signifique ser capaz de mostrar
para um acontecer no qual estamos enraizados e que somos
enquanto ser-no-mundo.

Nas aulas ministradas por ocasião do Curso durante o semestre de Inverno de 1955/56, na Universidade de Freiburgo i. Br., bem como na Conferência proferida a 25 de Maio de 1956, no Club zu Bremen, e a 24 de Outubro de 1956, na Universidade de Viena, Heidegger expõe seu pensamento sobre o princípio do fundamento. Assim, também, em seu tratado A Essência do Fundamento, em 1928, traça linha análoga.

Na primeira aula do citado Curso, a afirmação: "Nada é sem fundamento"

vigente. Depois da Filosofia da subjetividade, entramos num novo modo de fazer Filosofia. A vertente hermenêutica que recorre aos dois teoremas do círculo hermenêutico e da diferença ontológica define uma posição filosófica a partir de onde se faz a introdução dos princípios epocais, desde uma nova compreensão do ser."

${ }^{3}$ No contexto, fundamentar um sentido de justificação de ordem transcendental. Quando se fala em fundamento sem fundo, quer-se dizer algo da impossibilidade de se afirmar um fundamento inconcusso ou um fundamento absoluto (STEIN, 2004, p.151).

${ }^{4}$ Kant introduziu o transcendental no sentido de condição de possibilidade do conhecimento e dos objetos do conhecimento. Situava-o, no entanto, na subjetividade. Hoje, no entanto, muitos autores foram além desse conceito clássico e falam de uma transcendentalidade não-clássica que toma diversos sentidos, conforme a Filosofia em que ela é utilizada (STEIN, 2004, p.151-152). 
(HEIDEGGER, 1999, p. 12). O princípio do fundamento reza: nilhil est sine ratione, ou seja, nada é, na verdade, sem fundamento. Isto quer dizer: "Nada daquilo que de certo modo é, o é sem fundamento" (HEIDEGGER, 1999, p. 14). Cada ente que é de certa maneira possui um fundamento, não sendo este nem uma verificação, nem uma regra. A questão que se põe é a seguinte: sobre o que se fundamenta o princípio do fundamento? O princípio do fundamento é um princípio fundamental, ou seja, é o princípio fundamental de todos os princípios fundamentais (HEIDEGGER, 1999, p. 18).

Dito de outra forma: o princípio do fundamento é o supremo dos princípios fundamentais (HEIDEGGER, 1999, p. 20). Ele se encontra numa região obscura. ${ }^{5}$ Nesse sentido, na sétima aula do curso, o filósofo Martin Heidegger manifesta que o princípio do fundamento "é um daqueles princípios que silenciam aquilo que thes é mais próprio. O silenciado é aquilo que não é pronunciado. Ouvir o inexpressado exige um ouvido que cada um de nós tem e nenhum usa corretamente" (HEIDEGGER, 1999, p. 72).

No que concerne ao silêncio, é o esquecimento do ser enquanto somos incapazes de pensá-lo em sua essência que caracteriza a questão central da metafísica clássica. Observa-se o conhecimento humano atrelado a princípios supremos esclarecedores, claros e inabaláveis (fundamentum inconcussum).

No pensamento heideggeriano, ser e fundamento estão entrelaçados; ser é em sua essência fundamento. O filósofo ilumina as suas lições afirmando que, segundo o princípio do fundamento, somente $o$ ente é respectivamente fundamentado, já que ao ser pertence fundamento. Isso quer dizer que o ser enquanto ser é fundado e apenas o ente tem sempre o seu fundamento. Por essa razão, o ser nunca pode anteriormente ter um fundamento, que o deva fundamentar. Ora, o fundamento do ser é sem-fundo (Ab-Grund), ${ }^{6}$ abissal.

Entretanto para alcançarmos a área do estado-de-coisas, na qual o princípio do fundamento é entendido enquanto princípio do ser, torna-se necessário realizar

\footnotetext{
${ }^{5} \mathrm{O}$ filósofo afirma: "Para onde quer que olhemos, a discussão do princípio do fundamento cai, logo nos primeiros passos, na obscuridade. [...] O claro e a luz precisam no entanto do obscuro e da sombra, senão nada haveria para elucidar" (HEIDEGGER, 1999, p. 21).

${ }^{6}$ Nesse sentido, destacamos o fio condutor traçado no artigo de Lenio Streck (STRECK, 2004, p. 4447).
} 
um "salto". Segundo Heidegger (1999, p. 83), "o salto leva o pensamento sem pontes, isto é sem a constância de uma progressão, para uma área e uma outra maneira do dizer". Dessa maneira, o princípio do fundamento não é apenas princípio como um princípio fundamental supremo; ele é um princípio no sentido insigne, já que é um salto.

No sentido de um tal salto, o princípio do fundamento é um princípio na essência do ser. Na realidade nós não podemos continuar a dizer que o princípio do fundamento é um princípio do ser, mas devemos dizer: o princípio do fundamento é um princípio no ser como ser, isto é como fundamento (HEIDEGGER, 1999, p. 84).

Antes de atingir a essência do princípio do fundamento, nas aulas 1 a 6 por ocasião do Curso, durante o semestre de Inverno de 1955/56, na Universidade de Freiburgo i. Br., nota-se desvios em torno do princípio do fundamento. Na ocasião, Heidegger (1999, p. 89-90) destacou cinco coisas mais importantes encontradas em torno do princípio do fundamento. São elas a preparação do salto do princípio do fundamento para o princípio do ser, designadas da seguinte forma: 1. A incubação do princípio do fundamento; 2. A ordenação do princípio do fundamento como um princípio fundamental supremo; 3. A reivindicação do princípio do fundamento como o princípio mais poderoso, que define a nossa era; 4. O fundamento como "porquê" e como "porque" e 5. A mudança de tonalidade no princípio do fundamento.

A primeira coisa principal é o período de incubação do princípio do fundamento. Nessa fase do pensamento ocidental, o ser ainda dorme. A incubação está relacionada à história da metafísica antiga e medieval que, na pergunta pelo ente enquanto tal, o ser sempre se manifestou de forma inessencial. Esta é a época enquanto o ser se subtrai. É neste retirar-se que se oculta a essência do ser (HEIDEGGER, 1999, p. 84-85). A segunda coisa mencionada por Heidegger (1999) é a ordenação do princípio do fundamento como um princípio fundamental supremo. Leibniz fixou o princípio do fundamento na versão rigorosa do principium reddendae rationis. $^{7}$

\footnotetext{
7 Segundo Heidegger (1999, p.39-40), "Leibniz escreve num dos últimos ensaios (Specimen inventorum, Philos. Schriften ed. Gerhardt VII, 309): duo sunt prima principia omnium tatiocinationum, Principium nempe contradictionis... et principium reddendae rationis; 'há dois princípios superiores para todos os procedimentos demonstrativos, o princípio - entende-se - da contradição e o princípio
} 
Nessa fase, o ente aparece como objeto e o ser chega à aparência, enquanto a objetualidade dos objetos. Esta objetualidade em relação recíproca alcança a subjetividade dos sujeitos. Ser enquanto a objetualidade dos objetos é fixado na relação com a representação do sujeito (HEIDEGGER, 1999, p. 86). O método que destina o ser na objetualidade dos objetos, que se retira na sua essência como ser, define a Era Moderna. Neste momento, o período de incubação do princípio do fundamento chega a seu fim (HEIDEGGER, 1999, p. 85).

A terceira das cinco coisas mencionadas por Heidegger é a reivindicação do princípio do fundamento como o princípio mais poderoso, que define a nossa era. É a característica da Era Atômica, como aquela que está sujeita ao poder do principium reddendae rationis sufficientis. ${ }^{8}$ É a reivindicação à entrega do fundamento suficiente para tudo que é concebido. A natureza tornou-se um objeto e uma representação, que põem em relevo e assegura os seus fenômenos como uma existência calculável (HEIDEGGER, 1999, p. 87).

A quarta coisa principal é relacionada ao fundamento como "porquê" e como

reddendae rationis. Este princípio mencionado em segundo lugar diz, quod omnis veritatis reddi ratio potest (ib.), 'que para cada verdade (isto é, segundo Leibniz, para cada verdadeiro princípio) pode ser concedido um fundamento'. O principium rationis é para Leibniz, pensado rigorosamente, o principium reddendae rationis. Rationem reddere significa: devolver o fundamento. Por que razão devolver e para onde dar de volta? Porque nos métodos demonstrativos, falando em geral do reconhecimento, tratando-se da re(a)-presentação dos ob-jetos, entra em jogo este 'devolver'. A linguagem latina da Filosofia di-lo mais claramente: o conceber é re-praesentatio. Aquilo que vem ao encontro, vem em direção ao eu representante, de volta para ele e é apresentado ao seu encontro, (de)posto num presente. Conforme o principium reddendae rationis, o representar tem de, caso pretenda que seja reconhecedora, dar de volta o fundamento daquilo que vem ao encontro ao representar, e isto quer dizer, dá-lo de volta a si mesmo (reddere). No representar re-cognitivo pelo principium rationis. $\mathrm{O}$ princípio do fundamento é por isso, para Leibniz, o princípio fundamental do fundamento a ser deposicionado".

${ }^{8}$ Nestes lindes, Heidegger (1999, p. 53) caracteriza a Era Atômica como "época planetária da Humanidade pelo fato do poder do princípio magno, do principium reddendae rationis, se desenvolver de um modo expatriado na área determinante da existência do homem, se não mesmo a desencadeia. Quando a palavra 'expatriado' (unheimlich) é aqui utilizada não o é em sentido sentimental. É para que pensemos literal e objetivamente que o singular desencadeamento da reivindicação à entrega (Zu-stelling) do fundamento ameaça tudo o que é pátrio (Heimische) do homem e lhe rouba qualquer fundamento e solo para o enraizamento, isto é, para aquilo a partir do qual até agora cresceu cada uma das grandes Eras da Humanidade, cada espírito aberto para o mundo, cada formação da figura humana.

Assim evidencia-se uma situação extremamente estranha do homem moderno, uma tal que vai contra todas as opiniões habituais das representações quotidianas, na qual nós vagueamos como cegos e surdos: a reivindicação do princípio magno do fundamento a ser entregue retira ao homem contemporâneo o enraizamento. Também podemos dizer: quanto mais decisivamente for forjada a corrida para a sujeição das enormes energias, através da qual a necessidade energética do homem sobre a Terra deverá ser coberta para todos os tempos, tanto mais escassa será a riqueza do homem, na área do essencial para construir e habitar. Isto é um enigmático contraste entre a reivindicação à entrega do fundamento e a perda." 
"porque". A base da reflexão está fulcrada sobre um Aforismo de Angelus Silesius, contemporâneo mais jovem de Leibniz. Diz o aforismo: "A rosa é sem porquê; ela floresce, porque floresce, Ela não repara em si própria, não pergunta, se a vemos" (HEIDEGGER, 1999, p. 67). Heidegger (1999, p. 88) afirma: "A rosa é sem porquê, mas não sem fundamento. $O$ 'porquê' nomeia o fundamento, que sempre fundamenta assim, que ele é simultaneamente apresentado como fundamento". O "porque" do aforismo indica o florescer remetendo-o a si próprio, isto é, o florescer funda-se a si próprio. O florescer é puro abrir-se-a-partir-de-si-próprio, puro brilhar. Assim, o "porque" menciona o fundamento, mas este é no aforismo o simples florescer da rosa, o ser-rosa (HEIDEGGER, 1999, p. 89).

A quinta e última questão apresentada é a mudança de tonalidade no princípio do fundamento. Em vez de "Nada é sem fundamento", Heidegger entoa "Nada é sem fundamento", ou seja, o tom deslocou do "nada" para o "é" e do "sem" para o "fundamento". A questão é que a palavra "é" nomeia de alguma forma o ser. Destarte, o deslocamento do tom na referida frase permite ouvir uma consonância de ser e fundamento. O princípio fala agora do ser. ${ }^{9}$

Portanto, poderíamos entender que o ser tem fundamento, isto é, o ser é fundamentado. Disso não existe referência com o principium rationis, uma vez que, segundo tal princípio do fundamento, apenas o ente é respectivamente fundamentado. Desta sorte, em consequência disso, a nova tonalidade põe a descoberto o princípio do fundamento como um princípio do ser (HEIDEGGER, 1999, p. 80).

\section{O FUNDAMENTO EM HEIDEGGER}

\footnotetext{
${ }^{9}$ Nas lições de Heidegger (1999, p.132), interessante destacar a harmonia do sentido do princípio com seu sentido musical. Através do sentido musical entende a relação perfeita com o princípio do fundamento da seguinte forma: "Se entendermos a palavra 'princípio' no sentido musical, então é válido para o nosso caminho através do princípio do fundamento, aquilo que uma vez Bettina v. Arnim escreve no seu livro 'Goethes Briefwechsel mit einem Kinde' (Correspondência de Goethe com uma Criança): 'Quando na música se fala de uma frase e de como ele é executado, ou do acompanhamento de um instrumento e do entendimento com o qual ele é tratado, aí eu penso exatamente o contrário, que $\mathrm{o}$ andamento executa $\mathrm{o}$ músico, que o andamento tantas vezes se apresenta, se desenvolve, se concentra, até que o espírito totalmente nele se estabelece.' (Obras Completas, ed. Oehlke. Vol. III, p.168)."
} 
A proposta de Heidegger (1999, p. 103) é pensar o fundamento como o ser e o ser como fundamento, ou seja, isto representa não mais explicar o ser através de algo que é ente. É neste momento que aparece a importância do salto como ouvir o princípio do fundamento como um princípio do ser.

O salto desprende-se de uma e a partir de uma área de desprendimento. O salto abandona esta área e não a deixa contudo atrás de si. Através do abandonar o salto recupera a área de desprendimento de uma nova forma, e decerto não apenas na margem senão necessariamente. O salto é um salto essencialmente retrospectivo. O que nós apreendemos na retrospectiva das coisas principais, tentamos manter uniforme, ao caracterizarmos o traço principal da área de desprendimento.

Esta área mostrou-se-nos como a história do pensamento ocidental. No respeitante a ela falou-se de destino do ser. Aquilo que é válido ouvir na segunda tonalidade do princípio do fundamento como o princípio do ser, não é de modo algum de tal gênero, que nós ainda não o tivéssemos ouvido de todo. Isso é, pelo contrário, de um tal gênero que nos reivindica na nossa essência, bem entendido: na nossa essência. Isto quer dizer: a reivindicação do ser instala primeiramente o homem na sua essência. No destino do ser e a partir dele somos nós em primeiro lugar destinação (geschicklich) e como essência destinada somos obrigados a encontrar o destinado (Schickliche), e isto quer dizer sempre simultaneamente enredado nosso, a malograrmos o destinado (HEIDEGGER, 1999, p. 103).

A história do pensamento ocidental é a história do ser como retirada. A área de desprendimento é a história do pensamento ocidental, experimentada como destino do ser (HEIDEGGER, 1999, p. 137); é a história do destino do ser. Um traço fundamental do ser é o seu desocultar-se. Este desocultar não é atributo do ser, senão o próprio ser, ou seja, o ser tem o seu ser próprio no desocultar-se. E dessa maneira, Heidegger (1999, p. 104) afirma:

O ser não é anteriormente algo por si, que é depois em primeiro lugar realizado por um desocultar-se. Desocultar-se não é um atributo do ser, senão: desocultar-se pertence à propriedade do ser.

Este desocultar-se perdura enquanto ocultar-se e é apenas na medida em que o homem, segundo sua essência se encontrar numa clareira do ser, será ele um ser pensante. Somente o desvelamento do ser possibilita a revelabilidade do ente. Este desvelamento, como verdade sobre o ser, é chamado por Heidegger (1988, p. 23) de verdade ontológica. A história do pensamento é o envio da essência do 
homem a partir do destino do ser (HEIDEGGER, 1999, p. 128). Desta forma, o destino do ser permanece em si a história essencial do homem ocidental, na medida em que o homem histórico é necessário no habitar edificante da clareira do ser (HEIDEGGER, 1999, p. 137). É no salto que encontramos o mais digno de ser pensado (HEIDEGGER, 1999, p. 131).

O pensar deve dar o salto sempre de novo e primordialmente. Neste sempre iniciado dar o salto não há qualquer repetição e qualquer regresso. É necessário o salto, até que o antepensar recordante no ser como ser tenha se transformado, a partir da verdade do ser, num outro dizer (HEIDEGGER, 1999, p. 139).

Portanto, re-cordar o sido é ante-pensar no impensado a-ser-pensado. ${ }^{10}$ Isto quer dizer que em Heidegger o princípio do fundamento não é pensado conforme a metafísica clássica, mas sim pensado como um princípio histórico-ontológico. Historica-ontologicamente, ser e fundamento "são" o mesmo (HEIDEGGER, 1999, p. 160). É neste sentido que não podemos pensar o ser a partir do ente; não podemos pensar o ser como ratio, como causa primordial, como fundamento racional, mas sim ser e fundamento como uma pertença recíproca. E na medida que o ser se desdobra como fundamento, não tem ele próprio um fundamento, porque qualquer fundamentação teria de minimizar o ser a algo como ente.

Heidegger afirma: "Ser permanece como ser, destituído de fundo. Do ser permanece o fundamento, isto é como fundamento primeiramente fundamentador, de fora e separado. Ser: o sem-fundo" (HEIDEGGER, 1999, p. 160-161). Fundamento significa, "pensado na totalidade", a área situada profundamente e que ao mesmo tempo sustenta. ${ }^{11}$ Assim, o princípio do fundamento é sem-fundo.

${ }^{10}$ Esta interessante frase é formulada por Heidegger (1999, p.138-139) na décima segunda aula do
Curso referido onde o filósofo ensina que o "salto no desprendimento não desvia de si a área de
desprendimento, senão que o salto torna-se ao saltar na apropriação monumental do destino do ser.
O próprio salto exprime o seguinte: ele não salta nem para a fora da área de desprendimento, nem
adiante para uma zona separada por si. O salto permanece salto apenas como memorial. Re-cordar,
isto é o destino sido, exprime contudo: refletir, e na verdade sobre aquilo ainda impensado no sido
como o a-ser-pensado. A este corresponde o pensar apenas como ante-pensado. Re-cordar o sido é
ante-pensar no impensado a ser-pensado. Pensar é antepensar recordando. Isso não adere
historicamente representado ao sido como algo passado, nem olha fixamente concebido com a
impertinência do profético para um fictício futuro consciente. O pensamento recordante-antepensante
é o dar o salto. Este salto é um princípio, ao qual o pensamento se submete.
Heidegger (1999, p. 141) explica que fundamento designa "por um lado a profundidade, por
exemplo, o fundo do mar, o fundo do vale, a pradaria, um terreno e um solo em depressão, situados 
Portanto, o salto é um salto para o abismo, isto é, é o abissal da história da verdade do próprio ser. Em sua obra Identidad Y Diferencia, Heidegger (1990, p. 78-79) questiona

\begin{abstract}
¿A dónde salta el salto cuando salta desde el fundamento? ¿Salta a um abismo? Sí, mientras nos limitemos a representar el salto, y en concreto, em el horizonte del pensar metafísico. No, mientras saltemos y nos dejemos ir. ¿A dónde? Allí, a donde estamos ya admitidos: la pertenencia al ser. Pero el ser mismo nos pertenece, pues sólo em nosotros puede presentarse como ser, esto es, llegar a la presencia.

Por tanto, para exeprimentar propiamente la mutua pertenencia de hombre y ser, es necesario un salto, es necesaria la brusquedad de la vuelta sin puentes al interior de aquella pertenencia que es la primera en conceder la mutua relación de hombre y ser, y, con ello, la constelación de ambos. El salto es la puerta que abre bruscamente la entrada al dominio em el que el hombre y el ser se han encontrado desde siempre en su esencia porque han pasado a ser propios el uno del outro desde el momento em el que se han alcanzado. La puerta de entrada al dominio en donde esto sucede, acuerda y determina por vez primera la experiencia del pensar.
\end{abstract}

A diferença entre um ente e outro é a diferença ôntica e a diferença ontológica é aquela diferenciação do ente e do seu ser. É esta diferenciação entre o ente e seu ser que constitui a essência da metafísica, a sua meta. Nesse sentido, o filósofo afirma:

la diferencia de ente y ser es el ámbito dentro del cual la metafísica, el pensamiento occidental en la totalidad de su esencia, puede ser lo que es. Por ello, el pasa atrás va desde la metafísica hasta la esencia de la metafísica (HEIDEGGER, 1990, p. 115).

Daí a transposição para o ser através do ente, já que quando Heidegger problematiza a diferença ontológica, está buscando, destarte, retomar a diferença metafísica entre ser e ente. Logo, ser é ser do ente, o ente é o ente do ser; ser e ente aparecem sempre no mesmo modo a partir da diferença. Por conseguinte, "lo

profundamente; no sentido mais vasto significa a terra, o solo da terra. Ainda mais primordialmente fundamento exprime ainda hoje na área linguística suabo-alemã tanto como humo. Isso é o fundo crescido, o pesado e fértil solo da terra. Um canteiro de flores, por exemplo, tem muito pouco fundo, o qual deverá primeiramente ser fornecido para um crescimento favorável. Fundamento significa, pensado na totalidade a área situada profundamente e que ao mesmo tempo sustenta. Assim falamos nós do fundo do coração." 
único que está claro es que cuando se habla del ser de lo ente y de lo ente del ser, se trata siempre de una diferencia" (HEIDEGGER, 1990, p. 135). "La diferencia constituye el proyecto en la construcción de la esencia de la metafísica" (HEIDEGGER, 1990, p. 153).

Importa destacar, ainda, que é a transcendência o recinto da questão em torno do fundamento. A transcendência heideggeriana significa ultrapassagem. $\mathrm{O}$ transcendente (que transcende) é o que realiza a ultrapassagem, persiste na ação de ultrapassar. Esta transcendência, na significação terminológica que importa clarificar e apresentar, significa o que é próprio do estar-aí humano (HEIDEGGER, 1988 , p. 33). Esta transcendência mediante uma análise do conceito de mundo, determina-se como ser-no-mundo do estar-aí (ser-aí, pre-sença, Dasein) (HEIDEGGER, 1988, p. 85).

\section{REFERÊNCIAS}

HEIDEGGER, Martin. A Essência do Fundamento. Tradução Artur Morão. Lisboa: Edições 70, 1988.

. Identidad Y Diferencia. Tradução Helena Cortés e Arturo Leyte. Barcelona: Anthropos Editorial, 1990. $\overline{\text { Piaget, }} 1999$.

O Princípio do Fundamento. Tradução Jorge Telles Menezes. Lisboa: Instituto

STEIN, Ernildo. Exercícios de Fenomenologia: Limites de um Paradigma. ljuí, Rio Grande do Sul: Unijuí, 2004.

STRECK, Lenio Luiz. Os métodos de interpretação, a Metafísica e de como não há um Grundmethode na Hermenêutica: um contributo à luz do Ontological Turn. In: MELLO, Cleyson de Moraes; FRAGA, Thelma Araújo Esteves (Org.). Novos

Direitos: os paradigmas da pós-modernidade. Niterói: Impetus, 2004. p.44-47. 